\title{
Psychological Autopsy and Forensic Considerations in Completed Suicide of the SARS-CoV-2 Infected Patients. A Case Series and Literature Review
}

\author{
Roxana-Mihaela Crisan ${ }^{1,2}$, Ciprian Ionut Bacila ${ }^{3, *}$, Bogdan Neamtu ${ }^{4,5}$, Adrian Nicolae Cristian ${ }^{2,6}$, \\ Elena Topîrcean ${ }^{2,6}$, Adriana Popescu ${ }^{4}$ and Silviu Morar ${ }^{2,6}$
}

Citation: Crisan, R.-M.; Bacila, C.I.; Neamtu, B.; Cristian, A.N.; Topîrcean, E.; Popescu, A.; Morar, S.

Psychological Autopsy and Forensic Considerations in Completed Suicide of the SARS-CoV-2 Infected Patients. A Case Series and Literature Review. Appl. Sci. 2021, 11, 11547. https:// doi.org/10.3390/app112311547

Academic Editors: Diac Madalina,

Diana Bulgaru Iliescu and

Francesco Cappello

Received: 25 September 2021

Accepted: 2 December 2021

Published: 6 December 2021

Publisher's Note: MDPI stays neutral with regard to jurisdictional claims in published maps and institutional affiliations.

Copyright: (c) 2021 by the authors Licensee MDPI, Basel, Switzerland. This article is an open access article distributed under the terms and conditions of the Creative Commons Attribution (CC BY) license (https:// creativecommons.org/licenses/by/ $4.0 /)$.
1 Doctoral Department, Faculty of Medicine, Lucian Blaga University from Sibiu, 550024 Sibiu, Romania; crisanrox@gmail.com

2 Forensic Department, County Clinical Emergency Hospital of Sibiu, Corneliu Coposu Boulevard 2-4, 550245 Sibiu, Romania; adrian.cristian@ulbsibiu.ro (A.N.C.); elena.topircean@ulbsibiu.ro (E.T.); silviu.morar@ulbsibiu.ro (S.M.)

3 Dental Medicine and Nursing Department, Faculty of Medicine, Lucian Blaga University from Sibiu, "Gh. Preda" Clinical Pshychiatry Hospital, 550024 Sibiu, Romania

4 Clinical Department Faculty of Medicine, Lucian Blaga University from Sibiu, 550024 Sibiu, Romania; bogdan.neamtu@ulbsibiu.ro (B.N.); adriana.popescu@ulbsibiu.ro (A.P.)

5 Research Department, Pediatric Clinic, Pediatric Clinical Hospital Sibiu, 550166 Sibiu, Romania

6 Preclinical Department, Faculty of Medicine, Lucian Blaga University from Sibiu, 550024 Sibiu, Romania

* Correspondence: ciprian.bacila@ulbsibiu.ro; Tel.: +40-0723-000-227

Abstract: Our paper aims to present three cases of committed suicide in SARS-CoV-2 infection during the quarantine period. We investigated if there is a role for the infection itself in triggering the suicidal act or if it is augmented by other risk factors such as fear, psychosocial stress, lifestyle changes, and social isolation. To this goal, we analyzed the clinical, paraclinical, histopathological, toxicological records, mental health conditions, psychological, social, cultural, and economic aspects in detail. One patient committed suicide at home, by hanging, while the other two during hospitalization in the red zone, within the Sibiu County Emergency Clinical Hospital, hanging and falling from a height, respectively. The autopsy was carried out within the restricted area for COVID-19 in Sibiu County Forensic Medicine Service. Patients' medical histories were analyzed based on the available medical reports. Additionally, we interviewed a family member, applying the so-called psychological autopsy method, based on open-ended questions and standardized instruments (questionnaire) to point out the motives and behavioral changes that might explain the committed suicide. With this data, we could fulfill a design to elucidate and outline the reasons for the suicidal act. Our findings showed that the mental state deteriorated progressively, both in preexisting depressive and non-depressive backgrounds. Furthermore, we highlight the COVID-19 psychological impact in the suicidal acts. Further on, we reviewed the risk factors presented in the literature that are associated with mental health problems and behavioral changes such as stress, anxiety, depressions, sleep disorders, impulsivity, loneliness.

Keywords: completed suicide; psychological autopsy; SARS-CoV-2; risk factors; depression

\section{Introduction}

Nearly 800,000 people die each year from suicide [1]. The COVID-19 pandemic is a global concern for the healthcare systems and governments worldwide, challenged to face related implications. People's lives have changed radically because of the authorities isolation rules and social distancing. Moreover, uncertainty concerning public safety still impacts individuals' mental health, including depression, anxiety, and stress disorders [2] All the pandemic problems, such as positive infection diagnosis, isolation, quarantine, social distancing, economic consequences, can trigger psychological factors, such as sadness, 
anxiety, fear, anger, annoyance, frustration, guilt, helplessness, loneliness, and nervousness. These typical behavioral changes that many individuals experience during the crisis, might have serious consequences affecting their lives [2]. The influence of committed suicide rates for the patients infected with SARS-CoV-2 is scarcely referred to in the literature, and mental health clinicians should not lose sight of suicide prevention on these people [3]. It is acknowledged that SARS-CoV-2 infections hallmark is the respiratory syndrome and a pro-inflammatory state with cerebral hypoxia triggering neuroinflammation [4]. The positive diagnosis of SARS-CoV-2 settles the background for the suicide risk factors affecting the psychological state in these patients. Therefore, a thorough assessment of these factors and the reasons that influenced the suicidal acts are needed in patients infected with SARS-CoV-2. The psychological autopsy applied helps gather enough data to reconstruct and understand the event in terms of plain physical health, spiritual beliefs, cognitive function, mental state, and social connection. At the same time, it helps the researchers differentiate more accurately the reasons for the loss of interest in life, the role played by the COVID-19 pandemic situation, and the SARS-CoV-2 infection in suicidal acts. Consequently, the psychological autopsy in patients with SARS-CoV-2 disease who committed suicide could offer effective prevention strategies for those at higher risk for suicidal ideation. First, the method paves the way for the analysis of the committed suicide precipitating factors. Second, it specifies the role played by the deceased himself in his death and his psychological state before the self-aggressive act. The suicidal process is a multifactorial phenomenon that needs to be analyzed to better focus on suicide prevention strategies. The current literature is scarce regarding psychological autopsy in COVID-19 patients with committed suicide [3,5].

This paper aims to report three completed suicide cases with antemortem SARS-CoV-2 infection, presenting an analysis of suicidal risk factors and suicidal behaviors based on postmortem psychological autopsy results. We referred to the current literature reports in this respect, performing a narrative review.

\section{Materials and Methods}

All cases were tested positive for SARS-CoV-2 infection on RT-PCR before the suicidal act. The autopsy was employed within the Sibiu Forensic Medicine Service, in the COVID19 restricted area, using complete protective equipment, collecting histopathological and toxicological analysis.

Two cases were hospitalized in the red area within the Sibiu County Emergency Clinical Hospital. The third case was quarantined, alone at home. Two patients were found dead by hanging, one patient was found fallen from a height, in the hospital yard, with a preserved state of consciousness, and was taken over by the emergency unit for investigations and specialized treatment. The medical records from the hospitalization period were analyzed in detail, highlighting these patients' physical and mental health conditions. For the case, found at home, we analyzed the recent medical records provided by the hospital and the family members. He tested positive for COVID-19 ten days before the committed suicide.

We complied with Helsinki Declaration principles regarding ethical considerations in analyzing the data. We ensured confidentiality in accordance with national and European legislation regarding data protection. All records of interest were collected to analyze the reasons and risk factors that led to suicide. Eventually, each patient signs and behavioral changes before the final decision to die by suicide were noted.

The deceased profile was recreated thoroughly interviewing the relatives in combination with all the data obtained using site investigation reports, death certificates, available medical documents, and medico-legal reports completed with histopathology and toxicology examinations.

For each of these three cases, the method of the psychological autopsy was applied. In addition, the information was collected from the relatives using a specially designed questionnaire. 
The family member's interviews combined open-ended questions with standardized instruments. The open-ended questions facilitated a free discussion to collect information about the trajectory and events in life, family relationships, and questions about alcohol drinking habits. In this part, we particularly focused on the roles of the SARS-CoV-2 infection, the COVID-19 pandemic, and the events closely related to the suicidal act. The standardized instruments gathered the data about the personal medical history, including psychiatric disorders and behavioral changes such as suicidal ideation, sadness, selfisolation, anxiety, aggression, nervousness, loneliness, insomnia, chronic fatigue, lack of communication with the family, feeling of worthlessness, feeling guilty, inferiority feeling complex, self-isolation, loss of interest in life.

The psychological profile and life's details represent an "open window" to the self, highlighting the suicidal motivation. All the analyzed details were important to determine the legal form of death, the objective criteria of forensic nature, and the judicial investigation data.

The questionnaire was structured on 20 items about the risk factors such as origin, education, profession, nationality, religion, family status, financial situation, date and place of death, alcohol consumption, medical conditions (including the details about the hospitalizations). It also included questions about suicidal past regarding possible attempts (where, when, how), the underlying conditions related to mental deterioration, and the behavioral changes closely before the tragic event.

Further on, we referred to our results in the context of other literature reports on the aforementioned risk factors. To this goal, we performed a narrative literature review in the discussion section presenting the potential triggers and mechanisms involved in the suicidal acts, focusing on the SARS-CoV-2 infection impact on the mental state of these patients. We search specific references using the Pubmed and Embase databases based on the keywords: "coronavirus", "suicide", "psychological autopsy", "risk factors".

\section{Results}

The risk factors in suicide etiopathogenesis, the psychological and behavioral changes are synoptically presented in Tables 1-3.

Table 1. The risk factors categories: demographics, medical records, and social factors.

\begin{tabular}{cccc}
\hline Risk Factors & Case 1 & Case 2 & Case 3 \\
\hline Demographics & & & Romanian \\
\hline Nationality & Hungarian & male & male \\
\hline Gender & male & 73 & 81 \\
\hline Age & 77 & urban & urban \\
\hline Residential status & urban & married & widowed for about one year \\
\hline Marital status & unmarried & Pentecostal & catholic \\
\hline Religion & Orthodox & two children & three children, two of them living \\
Number of children & without children & professional school & professional school \\
\hline Education & professional school & welder & welder \\
\hline Profession & crane driver & retired & retired \\
\hline Occupational status & retired & average financial income & average financial income \\
\hline Socio-economic status & average financial income & &
\end{tabular}


Table 1. Cont.

\begin{tabular}{|c|c|c|c|}
\hline Risk Factors & Case 1 & Case 2 & Case 3 \\
\hline \multicolumn{4}{|l|}{ Medical records } \\
\hline Organic diseases & $\begin{array}{ll}- & \text {-SARS-CoV-2 infection } \\
- & \text { urinary tract infection } \\
- & \text { prostate adenoma }\end{array}$ & $\begin{array}{ll}\text { - } & \text { SARS-CoV-2 infection } \\
\text { - } & \text { chronic ischemic car- } \\
\text { diomyopathy } & \\
\text { - } & \text { prostate adenoma }\end{array}$ & $\begin{array}{ll}- & \text {-SARS-CoV-2 infection } \\
- & \text { chronic liver disease } \\
- & \text { atherosclerosis } \\
- & \text { anemia }\end{array}$ \\
\hline Neuro-psychiatric diseases & depression & without diseases & depression \\
\hline $\begin{array}{c}\text { Family history of suicide } \\
\text { and neuropsychiatric } \\
\text { diseases }\end{array}$ & without & without & $\begin{array}{c}\text { depression-without suicidal } \\
\text { history }\end{array}$ \\
\hline $\begin{array}{l}\text { Suicide attempt in personal } \\
\text { history }\end{array}$ & without & without & without \\
\hline Alcohol drinking habits & occasional & not at all & daily \\
\hline \multicolumn{4}{|l|}{ Social factors } \\
\hline Social isolation & quarantined in hospital & quarantined in hospital & quarantined at home \\
\hline The place of the suicidal act & in hospital & in hospital & at home \\
\hline $\begin{array}{l}\text { The moment of the suicidal } \\
\text { act during the COVID-19 } \\
\text { pandemic }\end{array}$ & state of emergency & state of alert & state of alert \\
\hline $\begin{array}{l}\text { The period from the } \\
\text { SARS-CoV-2 infection } \\
\text { detection and the } \\
\text { suicidal act }\end{array}$ & 10 days & 30 days & 10 days \\
\hline
\end{tabular}

Table 2. Suicide motives and the psychological risk factors.

\begin{tabular}{lccc}
\hline Psychological Risk Factors & Case 1 & Case 2 & Case 3 \\
\hline Illness & & $\checkmark$ & $\checkmark$ \\
\hline Death of a family member & - & $\checkmark$ & $\checkmark$ \\
\hline Quarantine due to SARS-CoV-2 infection & $\checkmark$ & $\checkmark$ & $\checkmark$ \\
\hline Fear of spreading the SARS-CoV-2 infection to family members & - & $\checkmark$ & $\checkmark$ \\
\hline Acute stress disorder due to hospitalization in the red zone & $\checkmark$ & $\checkmark$ \\
\hline
\end{tabular}

Table 3. The most important behavioral changes noted after the psychological autopsy *

\begin{tabular}{|c|c|c|c|}
\hline Behavioral Changes & Case 1 & Case 2 & Case 3 \\
\hline sadness & $\checkmark$ & $\checkmark$ & $\checkmark$ \\
\hline anxiety & $\checkmark$ & $\checkmark$ & $\checkmark$ \\
\hline aggression & $\checkmark$ & $\checkmark$ & - \\
\hline nervousness & $\checkmark$ & $\checkmark$ & - \\
\hline loneliness & $\checkmark$ & $\checkmark$ & $\checkmark$ \\
\hline insomnia & $\checkmark$ & $\checkmark$ & $\checkmark$ \\
\hline chronic fatigue/restlessness & $\checkmark$ & $\checkmark$ & $\checkmark$ \\
\hline feeling guilty & - & $\checkmark$ & $\checkmark$ \\
\hline self-doubt & - & - & $\checkmark$ \\
\hline suicidal ideation & - & - & $\checkmark$ \\
\hline
\end{tabular}


Table 3. Cont.

\begin{tabular}{cccc}
\hline Behavioral Changes & Case 1 & Case 2 & Case 3 \\
\hline hardly cooperative with the treatment & & - & - \\
\hline lack of communication with the family, self-isolation & - & - & $\checkmark$ \\
\hline feeling of worthlessness & - & - & - \\
\hline loss of interest in life & - & - & \\
\hline * The patients informed their relatives on the phone about the behavioral changes. $\boldsymbol{V}$-yes, - no.
\end{tabular}

\subsection{Cases Presentation}

\subsubsection{Case 1}

The 77-year-old male patient was hospitalized during the state of emergency imposed by the Romanian governmental authorities at the beginning of the COVID-19 pandemic. He was admitted to the Infectious Diseases Department within the Sibiu County Emergency Clinical Hospital. The pulmonary CT performed revealed peribronchovascular interstitium lesions, alveolar condensations with a "ground glass" appearance, and fine fibrotic subpleural bands, on the left lower lobe.

At the admittance, he was tested positive for COVID-19 infection and the most important laboratory findings revealed lymphopenia, BUN and urinary retention, urinary tract infection biomarkers, an acute inflammatory syndrome, a clotting disorder syndrome and electrolytic impairments. The diagnoses were: (1) SARS-CoV-2 related pneumonia, (2) dyspeptic syndrome, (3) prostate adenoma, (4) sepsis with a urinary starting point, (5) acute kidney failure, (6) cytolysis syndrome, (7) electrolytic disorders, and (8) depressive syndrome. The prescribed treatment consisted of antidepressants (from the first day of admittance), antivirals (Lopinavir and Ritonavir), anti-inflammatory drugs (Plaquenil, Dexamethasone), antibiotics, diuretics, symptomatic, gastric protectors, vitamin therapy. The clinical symptoms related to the SARS-CoV-2 infection and the aforementioned pathologies improved, with the biomarkers within normal limits one day before his death. However, the patient's cooperation in receiving the treatment gradually became more difficult to achieve. After 12 days in the hospital and 10 days from the moment he found out he was infected with the SARS-CoV-2, he decided to commit suicide. The patient was found dead by hanging, with a lace tied to an aluminum bar, in the hospital's bathroom. No farewell letter was found at the scene. From the available medical documents, we noted that he was an introverted person, worked as a crane driver, drank alcohol only occasionally, was institutionalized in an asylum, and had a brother who died of cancer. The physical and histopathological examination concluded as a violent death due to mechanical suffocation by hanging. Brain examination revealed the presence of cerebral edema but with no other obvious pathological changes.

Blood probes harvested after the subject's death revealed 0\% grams blood alcohol concentration. The psychological autopsy data gathered from a relative are presented in Table 1

\subsubsection{Case 2}

The 73 years old male with chronic ischemic cardiomyopathy and benign prostatic hyperplasia was admitted to Sibiu Clinical Pneumology Hospital with SARS-CoV-2 related pneumonia (fever, cough, odynophagia). Chest radiography did not reveal any pulmonary consolidation areas. He was tested positive for SARS-CoV-2 infection on RT-PCR. The most important laboratory findings revealed lymphopenia, acute inflammatory syndrome, and a clotting disorder at the admittance. The medical treatment consisted of antivirals (Lopinavir and Ritonavir), anticoagulants (Clexane), anti-inflammatory drugs (Plaquenil, Dexamethasone, hydrocortisone hemisuccinate), antibiotics, antidepressives (alprazolam), symptomatic medication, gastric protection drugs, vitamins. Initially, the clinical condition worsened, but the infection, inflammation, and hepatic cytolysis syndrome were remit- 
ted later on. After ten days of hospitalization, antidepressive medication (alprazolam) was added.

On the day of his death, the patient suffered a polytrauma by falling from one level to another-throwing himself from the window in a suicide attempt. However, he did not lose his consciousness, stating that he intended to die by suicide. He was transported to the Emergency Reception Unit of the Sibiu Emergency Clinical Hospital to perform the necessary investigations and the appropriate specialized treatment, but the patient's condition worsened. Death was declared $11 \mathrm{~h}$ after the suicide attempt. The following diagnoses were established: right thoracic trauma with right hemopneumothorax, pulmonary and hepatic ruptures, hemoperitoneum, pertrochanteric fracture with displacement, hemorrhagic shock, traumatic shock, SARS-CoV-2 related pneumonia.

Blood probes harvested after the subject's death revealed 0\% grams blood alcohol concentration. The psychological autopsy data gathered from his relatives are presented in Table 1

\subsubsection{Case 3}

The last case presented is of an 81-year-old man, who had been hospitalized 15 days before his death in a community hospital in Sibiu County for orthostatic disorders with an altered general condition, on which occasion he underwent specialized examinations, including cranial CT (which did not detect any acute intracranial pathology). The most important laboratory findings revealed lymphopenia, macrocytic normochromic anemia and a hepatocytolisis syndrome.

His diagnostics were: (1) severe episode depressive disorders; (2) chronic liver disease, and (3) atherosclerosis. At discharge, the patient received prescriptions for an antidepressive treatment and on the day of release, the SARS-CoV-2 test was performed. The patient was already at home when he was informed about the test's positive result (10 days before his death). The mandatory quarantined period for 14 days at home was imposed. During this period, the patient had few symptoms. He was found dead on the first day of 2021, hanging from the access ladder of the house's attic; the investigations suggested the time of death occurring after midnight. A farewell letter was found on the spot, in which he apologized for his gesture, explaining the decision by the fact that he was very ill. As with the other cases, the autopsy examination concluded as a violent death was due to mechanical suffocation. Blood probes harvested after the subject's death revealed $0.97 \%$ grams blood alcohol concentration. The psychological autopsy data gathered from his relatives are presented in Table 1.

\section{Discussion}

During hospitalization, specific clinical symptoms in SARS-CoV2 infection improved under antiviral and anticoagulant treatment, correlating with the dynamics of hematological, inflammatory and coagulation biomarkers involved in thrombosis. Similar to our findings, the literature mentions the increased incidence of hypercoagulability state in COVID-19 patients with an increased consumption of clotting factors and platelets: elevated levels for D-dimers, prolongation of prothrombin time (PT), activated partial thromboplastin time (a-PTT), and thrombocytopenia [4,6,7]. Anti-COVID treatment was administered in two cases following the therapeutical protocols from that date. In the third case isolated at home, no specialized treatment was administered due to minimal symptoms. Death was a consequence of the suicidal act and was due to hemorrhagic and traumatic shock in one case and in the other two cases to mechanical asphyxiation by hanging.

Both the clinical and the biological evolution in these patients improved before the tragic event. However, the neuropsychiatric symptoms during the acute phase of infection or after the infectious episode were noted. 


\subsection{Neuronal Injury Mechanisms with a Potential Impact on Behavioral Changes}

Current literature points out the possibility that patients with SARS-CoV-2 infection might variably develop neurological symptoms prior, during, and even after the onset of common COVID-19 symptoms. SARS-CoV-2 directly affects the nervous system leading to hypercoagulability, metabolic or hypoxic injury, neuroinflammation and post-viral triggered autoimmune responses [8]. During the acute phase, the psychiatric manifestations mentioned in the literature were described in terms of psychosis, insomnia, changes in the general mood. Depression, anxiety disorders were reported in the post-illness stage $[9,10]$. The mechanisms by which CNS injury occurs are multiple: (1) Direct invasion by meningeal inflammation, impaired permeability of the blood-brain barrier (ACE receptors in endothelial cells, increased levels of IL- 6 and TNF- $\alpha$ ), and retrograde axonal transport (olfactory nerve fibers) [11-13], (2) cerebral hypoxia secondary to lung damage due to systemic inflammation stimulates neuroinflammation with significant cognitive and behavioral effects [14], (3) activation of a pro-inflammatory phenotype that focuses on the hyperactivity of glial cells and the consequently increased synthesis of cytokines (IL-6,12, TNF- $\alpha$ ) [8], (4) the state of hypercoagulability due to reduced ACE-2 receptors expression in infected endothelial cells with microvascular thrombosis and neurodegeneration. In COVID-19 patients with neurological sequelae, the histopathological findings in brain autopsy studies revealed erythrocytes extravasations in the parenchyma, fibrinoid deposits in the vessels, neuronal damage as a consequence of inflammatory infiltrate and intraparenchymal necrosis [13]. We could not document any of these pathological findings in the examined brain tissues, so it was difficult to point out compelling evidence of the SARS-CoV-2 infected neurons. Most probable, the other risk factors associated with the depression background in these cases played a crucial role in the outcome.

To further explore the link between neuronal injury and suicidal act we analyzed the exposure to toxic compounds. Two of the cases presented were professional welders. Welding fume is a complex mixture of different metals and most of the vapors contain a small amount of manganese. Many studies associate the potential neurological effects with manganese exposure in welding fumes [15-21]. The accumulation of manganese particles in neurons' mitochondria results in: (1) decreased cognitive abilities, (2) the appearance of hyperactive behavioral disorders (low levels of manganese), (3) Parkinsonism-like phenomena such as irritability, impulsiveness, agitation, obsessive-compulsive behavior, hallucinations, (4) cognitive deficits such as memory impairment, reduced learning capacity, decreased mental flexibility and cognitive slowing. However, national data in welders quality of life is scarce. Subsequent epidemiological studies should analyze this issue. Measures should be taken to protect the health of this socio-professional category or other socio-professional categories that might be at risk of neuronal injury [15]. Additionally, the psychological investigation could become a significant and mandatory element in these conditions.

We further analyzed the role of acute alcohol consumption in our cases. Alcohol consumption is known to be associated with depression [22]. Alcohol is a significant risk factor, especially on a depressive or neural injury background. Alcohol is acknowledged to have a role in augmenting impulsivity and self-aggression release. It increases both GABA-ergic activity that has an inhibitory role and the serotonergic activity with effects on behavior. The inhibition of NMDA receptors (N-methyl-D-aspartate) results in reduced levels of norepinephrine and acetylcholine. This mechanism could promote depression and even initiate suicide if relevant risk factors such as a depressive background are associated [23]. We could document a blood alcohol level of $0.97 \%$ grams only in the case who died at home.

\subsection{Susceptibility Factors for the Psychiatric Disorders' Development}

The common background for all the subjects was the depressive episode at the time of the committed suicide. The interaction between genetic, environmental factors, and stressful events during life has been demonstrated in the mental disorders development 
such as major depressive, bipolar disorders and schizophrenia. The depressive disorder has a familial aggregation in $40-70 \%$ of cases, and the polymorphisms involve mainly the serotonergic system and elements of the HPA (hypothalamus-pituitary-adrenocortical) axis. In our case series, only one patient had heredocolateral antecedents that suggest a familial aggregation. The susceptibility to psychiatric pathologies is based on certain genetic polymorphisms and epigenetic variations in neurogenesis, neuronal differentiation, and dendrites development. Epigenetic remodeling may appear during adult life under the influence of environmental factors (drugs, chemical substances, psychosocial factors) [24]. In our case series, we might consider the welding fumes, alcohol consumption along with the psychosocial factors.

\subsection{Psychological Autopsy-Demographics}

It is acknowledged that committed suicide is conditioned not only genetically but also by the complex interaction between the psychological, cultural, social, and religious factors [25]. All the cases presented were males. Men always had higher suicide rates than women. Current sources indicate similar trends during the COVID-19 pandemic [26]. The presented cases were aged between 73 and 81 years old. Older people have a higher risk of suicide than other population segments, so we consider it is necessary and critical to focus on suicide prevention measures, especially in this age group [27,28]. Considering that the first suicide case and that the COVID-19 infection in Sibiu County was a person of Hungarian ethnicity, we investigated suicidal behavior among people of Hungarian ethnicity, confirming the existence of an increased rate of suicide in this population [29]. Religion has been carefully studied to highlight evidence linking religious affiliation to suicidal acts, but reports have been contradictory (protective versus risk factor). Religion could rather serve as an indicator of emotional well-being and psychosocial integration [30].

\subsection{The Psychological Risk Factors and the Behavioral Changes}

Psychological factors and behavioral changes are less quantifiable. The psychological framework of these patients might have been addressed either using the verbal autopsy or the psychological autopsy reports. In poorer countries where autopsies are rare, and death certificates are inaccurate (Africa, Asia, Latin America), the verbal autopsy has been used as an epidemiological instrument. Verbal autopsy interviews the close relatives about the deceased symptoms, complaints, treatment type, compliance, and duration, and the disease course prior to his death with a random re-interviewing of $5 \%$ of the reports to assess the reliability [31,32]. However, caution should be taken regarding this method's reliability, and other autopsy methods should be further performed for its validation [31]. Psychological autopsy adds more data to the verbal autopsy reports integrating site investigation reports, death certificates, available medical documents, and medico-legal reports completed with histopathology and toxicology examinations. It brings essential data related to the patients' profile when there is no farewell letter linking the motives with the ongoing health emergency [3,31,33-37].

Based on the applied questionnaire, we could document that SARS-CoV-2 infection in association with other diseases had a psychological impact on these patients in a specific manner: the loneliness and the quarantine obligation, the loss of a family member due to SARS-CoV-2 infection, the fear of spreading SARS-CoV-2 infection to the loved ones. The behavioral changes presented in all the cases were sadness, anxiety, loneliness, insomnia, chronic fatigue. The depressive background was noticed only in two cases playing an important role in the suicidal act. In the other case, depression has been diagnosed for the first time during hospitalization. In a relatively recent study (2017) on a large cohort of New Zealanders aged $>65$ years, loneliness, poor self-reported health, depression were documented as independent, predictive variables of death. A death wish was found in $9.5 \%$ of this population sample, hence a special attention should be given on the aforementioned predictors along with the age factor, especially in COVID-19 patients [37]. 
Other behavioral changes such as aggression, nervousness, guilt, self-doubt, suicidal ideation, reluctance and difficult cooperation with the medical treatment, lack of communication with the family, and self-isolation were present in at least two out of three cases. Additionally, there were changes in behavior with an increase in impulsivity and aggression, which are involved in suicidal behavior, especially if associated with alcohol dependence. All the aforementioned behavioral changes and the risk factors suggest that they might have attempted suicide due to acute stress disorders. Our findings are in line with other research reports during the COVID-19 pandemic [5,22,38-44]. Mounting evidence in the literature points out its role in this respect $[33,45,46]$. During the COVID19 pandemic, suicide rates had a nonlinear trend. A decreasing trend was recorded in COVID-19 outbreak, then, over an extended period, the rates increased [47]. People with pre-existing mental illness were more vulnerable to stress caused by various risk factors related to COVID-19 and isolation [2,3,48]. All the pandemic problems, such as positive infection diagnosis, isolation, quarantine, social distancing, the economic consequences, can trigger behavioral changes such as sadness, anxiety, fear, anger, annoyance, frustration, guilt, helplessness, loneliness, and nervousness, increasing the risk of the suicidal behavior, and the committed suicide. A study conducted in China showed a moderate to severe psychological impact at more than half of the population studied with mild to severe symptoms of depression and anxiety [49]. Moreover, the subjects diagnosed with COVID-19 had a higher level of suffering, anxiety, depression, and a deeper echo of the psychological impact that led to other mental health problems than those who did not become infected [49-53].

\subsection{Psychological Autopsy-Forensic Considerations}

The suicidal act occurred in the hospital in two of the presented cases. Only a small part (about $10 \%$ ) of suicides take place in controlled environments (hospitals, prisons, and police custody); the rest appear in the community [54]. Most deaths from hanging are suicidal in intent, according to the literature [55]. In the third case the suicide occurred at home. The suicide risk in people with SARS-CoV-2 infection, isolated at home, should not be neglected, regardless of the severity of the symptoms, especially if they are known to have insomnia, depressive syndromes or live alone. Two of the patients never expressed a desire for suicide, and during hospitalization, although they received antidepressive treatment, they did not mention any suicidal ideation. This might be crucial for monitoring and further evaluation of these patients, and the psychological autopsy highlights this issue. Many studies in the literature showed that more than $75 \%$ of patients who died by suicide denied suicidal ideation when asked by a healthcare professional even under antidepressive treatment [37]. In the third case, the suicidal idea was expressed a year ago from the tragic incident, immediately after the wife's death when he was diagnosed with depression. These suicidal thoughts became more "active" as a conscious desire for selfharm in his quarantine period. This concept of "active" suicide and the existence of specific, suicidal thoughts are properly referred to in the literature, and prophylactic intervention measures should be ensured to alleviate the mental health status [37]. Psychological autopsy has its role in this concern

\subsection{Future Perspectives}

The psychological profile of the SARS-CoV-2 infected people, who end up in the committed suicidal act, may be the basis for preventive measures against the emergence of suicide with a lethal effect on these patients. Such prophylactic measures may be applied to people with depressive syndrome or who may be susceptible to suicidal ideation. Hence, in addition to antidepressive drug treatment, neurofeedback approaches might alleviate the mental state condition for these patients [56-59]. Moreover, advanced medical laboratory methods using cytokines profiles and specific serum biomarkers such as glial fibrillary acidic protein (GFAp) or neurofilament light-chain (NfL) might offer a solution to predict the more serious forms of COVID-19 diseases with an impact in the astrocytic and axonal 
injury [60-62]. This approach might show promise to differentiate mild and severe COVID19 disease forms and their impact on nervous system injury, especially in depressive patients. Future studies in COVID-19 patients experiencing psychiatric symptoms could entail neuronal injury biomarkers that are correlated with behavioral changes. For this reason, we emphasize the need of machine learning prediction models based on the categorical variables presented in the questionnaire and proper preventive interventions for the people experiencing psychiatric symptoms and with an increased risk of suicide [63-65]. Psychological autopsy method applied on larger cohorts in multicentric clinical studies paves the way for developing this kind of models and preventive interventions.

\section{Conclusions}

Our research highlights that the mere presence and awareness of SARS-CoV-2 infection on a depressive background might trigger the suicide acts, even if the clinical severity of the infection is not significant. The SARS-CoV-2 condition itself has the psycho-emotional consequences that appeared on a background of depression or other neuropsychiatric diseases. Therefore, in association with other risk factors (gender, age, toxic compounds, alcohol consumption, organic diseases), SARS-CoV-2 infection played an important role in committed suicide. During this pandemic, we consider necessary to have a multidisciplinary approach to COVID-19 disease. This can lead to suicide prevention strategies designed for patients infected with SARS-CoV-2 that are to be implemented even from the first signs and symptoms observed in patients' behavior.

Author Contributions: Conceptualization, R.-M.C., S.M., C.I.B. and B.N.; methodology, R.-M.C., S.M., C.I.B. and B.N.; software, R.-M.C. and B.N.; validation R.-M.C., S.M., C.I.B. and B.N.; formal analysis R.-M.C., S.M., C.I.B., A.P., A.N.C., B.N. and E.T.; investigation, R.-M.C., S.M., C.I.B., A.P., A.N.C., E.T. and B.N.; resources R.-M.C., S.M., C.I.B., A.N.C., E.T., A.P. and B.N.; data curation, R.-M.C., S.M., C.I.B., A.N.C. and B.N.; writing-original draft preparation R.-M.C., S.M., C.I.B. and B.N.; writing-review and editing, R.-M.C., S.M., C.I.B., A.P., A.N.C., B.N. and E.T.; visualization, R.-M.C., S.M., C.I.B. and B.N.; supervision, S.M. and C.I.B.; project administration, R.-M.C., S.M. and C.I.B.; funding acquisition, R.-M.C., S.M., C.I.B., A.P., A.N.C., B.N. and E.T. B.N. has contributed substantially to the work reported and has an equal role with the main author. All authors have read and agreed to the published version of the manuscript.

Funding: This research received no external funding.

Institutional Review Board Statement: The study was conducted according to the guidelines of the Declaration of Helsinki, and approved by the Ethics Committee of Gh. Preda Clinical Psychiatry Hospital (11413/A8/24.09.2021).

Informed Consent Statement: Informed consent was obtained from all subjects involved in the study.

Data Availability Statement: The data presented in this study are available on request from the corresponding author. The data are not publicly available due to data protection legislation.

Acknowledgments: This work is part of the Ph.D. Thesis of candidate Roxana Mihaela Crisan under the supervision of Silviu Morar at the Lucian Blaga University.

Conflicts of Interest: The authors declare no conflict of interest.

\section{References}

1. WHO. Suicide Prevention. Available online: https://www.who.int/health-topics/suicide\#tab=tab_1 (accessed on 10 March 2021).

2. Mamun, M.A.; Griffiths, M.D. First COVID-19 suicide case in Bangladesh due to fear of COVID-19 and xenophobia: Possible suicide prevention strategies. Asian J. Psychiatry 2020, 51, 102073. [CrossRef]

3. Aquila, I.; Sacco, M.A.; Ricci, C.; Gratteri, S.; Ricci, P. Quarantine of the COVID-19 pandemic in suicide: A psychological autopsy. Medico-Legal J. 2020, 88, 182-184. [CrossRef] [PubMed]

4. Carsana, L.; Sonzogni, A.; Nasr, A.; Rossi, R.S.; Pellegrinelli, A.; Zerbi, P.; Rech, R.; Colombo, R.; Antinori, S.; Corbellino, M.; et al. Pulmonary post-mortem findings in a series of COVID-19 cases from northern Italy: A two-centre descriptive study. Lancet Infect. Dis. 2020, 20, 1135-1140. [CrossRef] 
5. Uğurlu, T.T.; Baltacı, A.S.; Akça, A.; Acar, K. COVID-19 ile İlişkili Bir Özkıyım Olgusu [A Case of Suicide Related with COVID-19]. Turk Psikiyatri Derg. 2020, 31, 290-293.

6. Suess, C.; Hausmann, R. Gross and histopathological pulmonary findings in a COVID-19 associated death during self-isolation. Int. J. Leg. Med. 2020, 134, 1285-1290. [CrossRef] [PubMed]

7. Bruce-Brand, C.; Allwood, B.W.; Koegelenberg, C.F.N.; Lalla, U.; Louw, E.; Diacon, A.H.; Schubert, P.T. Postmortem lung biopsies from four patients with COVID-19 at a tertiary hospital in Cape Town, South Africa. S. Afr. Med. J. 2020, 110, 1195-1200. [CrossRef]

8. Keyhanian, K.; Umeton, R.P.; Mohit, B.; Davoudi, V.; Hajighasemi, F.; Ghasemi, M. SARS-CoV-2 and nervous system: From pathogenesis to clinical manifestation. J. Neuroimmunol. 2021, 350, 577436. [CrossRef] [PubMed]

9. Rogers, J.P.; Chesney, E.; Oliver, D.; Pollak, T.A.; McGuire, P.; Fusar-Poli, P.; Zandi, M.; Lewis, G.; David, A. Psychiatric and neuropsychiatric presentations associated with severe coronavirus infections: A systematic review and meta-analysis with comparison to the COVID-19 pandemic. Lancet Psychiatry 2020, 7, 611-627. [CrossRef]

10. Troyer, E.A.; Kohn, J.N.; Hong, S. Are we facing a crashing wave of neuropsychiatric sequelae of COVID-19? Neuropsychiatric symptoms and potential immunologic mechanisms. Brain Behav. Immun. 2020, 87, 34-39. [CrossRef] [PubMed]

11. Linker, R.A.; Lühder, F.; Kallen, K.-J.; Lee, D.-H.; Engelhardt, B.; Rose-John, S.; Gold, R. IL-6 transsignalling modulates the early effector phase of EAE and targets the blood-brain barrier. J. Neuroimmunol. 2008, 205, 64-72. [CrossRef] [PubMed]

12. Cardona, G.C.; Pájaro, L.D.Q.; Marzola, I.D.Q.; Villegas, Y.R.; Salazar, L.R.M. Neurotropism of SARS-CoV 2: Mechanisms and manifestations. J. Neurol. Sci. 2020, 412, 116824. [CrossRef] [PubMed]

13. Baig, A.M.; Khaleeq, A.; Ali, U.; Syeda, H. Evidence of the COVID-19 Virus Targeting the CNS: Tissue Distribution, Host-Virus Interaction, and Proposed Neurotropic Mechanisms. ACS Chem. Neurosci. 2020, 11, 995-998. [CrossRef] [PubMed]

14. Sasannejad, C.; Ely, E.W.; Lahiri, S. Long-term cognitive impairment after acute respiratory distress syndrome: A review of clinical impact and pathophysiological mechanisms. Crit. Care 2019, 23, 1-12. [CrossRef] [PubMed]

15. Qin, J.; Liu, W.; Zhu, J.; Weng, W.; Xu, J.; Ai, Z.-S. Health Related Quality of Life and Influencing Factors among Welders. PLoS ONE 2014, 9, e101982. [CrossRef]

16. Laohaudomchok, W.; Lin, X.; Herrick, R.F.; Fang, S.C.; Cavallari, J.; Shrairman, R.; Landau, A.; Christiani, D.C.; Weisskopf, M.G. Neuropsychological effects of low-level manganese exposure in welders. NeuroToxicology 2011, 32, 171-179. [CrossRef] [PubMed]

17. Bowler, R.M.; Gocheva, V.; Harris, M.; Ngo, L.; Abdelouahab, N. Prospective study on neurotoxic effects in manganese-exposed bridge construction welders. Neurotoxicology 2011, 32, 596-605. [CrossRef] [PubMed]

18. Chang, Y.; Kim, Y.; Woo, S.-T.; Song, H.-J.; Kim, S.H.; Lee, H.; Kwon, Y.J.; Ahn, J.-H.; Park, S.-J.; Chung, I.-S. High signal intensity on magnetic resonance imaging is a better predictor of neurobehavioral performances than blood manganese in asymptomatic welders. NeuroToxicology 2009, 30, 555-563. [CrossRef]

19. Flynn, M.R.; Susi, P. Neurological risks associated with manganese exposure from welding operations-A literature review. Int. J. Hyg. Environ Health 2009, 212, 459-469. [CrossRef] [PubMed]

20. Chang, Y.; Jin, S.-U.; Kim, Y.; Shin, K.M.; Lee, H.J.; Kim, S.H.; Ahn, J.-H.; Park, S.-J.; Jeong, K.S.; Weon, Y.C.; et al. Decreased brain volumes in manganese-exposed welders. NeuroToxicology 2013, 37, 182-189. [CrossRef]

21. Bowler, R.M.; Gysens, S.; Diamond, E.; Nakagawa, S.; Drezgic, M. Manganese exposure: Neuropsychological and neurological symptoms and effects in welders. Neurotoxicology 2006, 27, 315-326. [CrossRef] [PubMed]

22. Sher, L. Alcohol consumption and suicide. QJM Int. J. Med. 2005, 99, 57-61. [CrossRef] [PubMed]

23. Pompili, M.; Serafini, G.; Innamorati, M.; Dominici, G.; Ferracuti, S.; Kotzalidis, G.D.; Serra, G.; Girardi, P.; Janiri, L.; Tatarelli, R.; et al. Suicidal Behavior and Alcohol Abuse. Int. J. Environ. Res. Public Health 2010, 7, 1392-1431. [CrossRef] [PubMed]

24. Quattrocchi, A.; Del Fante, Z.; Di Fazio, N.; Romano, S.; Volonnino, G.; Fazio, V.; Santoro, P.; De Gennaro, U. Personalized medicine in psychiatric disorders: Prevention and bioethical questions. Clin. Ter. 2019, 170, e421-e424. [PubMed]

25. Turecki, G.; Brent, D.A. Suicide and suicidal behaviour. Lancet 2016, 387, 1227-1239. [CrossRef]

26. Khan, A.R.; Ratele, K.; Arendse, N. Men, Suicide, and COVID-19: Critical Masculinity Analyses and Interventions. Postdigital Sci. Educ. 2020, 2, 651-656. [CrossRef]

27. Conwell, Y.; Duberstein, P.R. Suicide in Elders. Ann. N. Y. Acad. Sci. 2006, 932, 132-150. [CrossRef] [PubMed]

28. Conwell, Y.; Van Orden, K.; Caine, E.D. Suicide in Older Adults. Psychiatr. Clin. N. Am. 2011, 34, 451-468. [CrossRef] [PubMed]

29. Rihmer, Z.; Gonda, X.; Kapitany, B.; Dome, P. Suicide in Hungary-epidemiological and clinical perspectives. Ann. Gen. Psychiatry 2013, 12, 21. [CrossRef]

30. Lawrence, R.E.; Oquendo, M.A.; Stanley, B. Religion and Suicide Risk: A Systematic Review. Arch. Suicide Res. 2015, $20,1-21$. [CrossRef] [PubMed]

31. Benbow, E.W.; Roberts, I.S.D. The autopsy: Complete or not complete? Histopathology 2003, 42, 417-423. [CrossRef]

32. Gajalakshmi, V.; Peto, R. Verbal autopsy of 80,000 adult deaths in Tamilnadu, South India. BMC Public Health 2004, 4, 47. [CrossRef]

33. Buschmann, C.; Tsokos, M. Corona-associated suicide-Observations made in the autopsy room. Leg. Med. 2020, 46, 101723. [CrossRef] [PubMed]

34. Padubidri, J.R.; Rao, S.J.; Dutt, A.; Shetty, B.S.K.; Boloor, A. Psychological Autopsy- Unraveling the Mystery of Death. Austin J. Forensic Sci. Criminol. 2015, 2, 1025. 
35. Bastia, B.K.; Kar, N. A Psychological Autopsy Study of Suicidal Hanging from Cuttack, India: Focus on Stressful Life Situations. Arch. Suicide Res. 2009, 13, 100-104. [CrossRef] [PubMed]

36. Majid, A.; Suhaff, A.A.; Khan, A.W. Psychological Autopsy: Reconstructing the Mystery of Suicide. Indian J. Priv. Psychiatry 2017, 11, 24-25. [CrossRef]

37. Harmer, B.; Lee, S.; Duong, T.V.H.; Saadabadi, A. Suicidal Ideation. In StatPearls; StatPearls Publishing: Treasure Island, FL, USA, 2021.

38. Griffiths, M.D.; Mamun, M.A. COVID-19 suicidal behavior among couples and suicide pacts: Case study evidence from press reports. Psychiatry Res. 2020, 289, 113105. [CrossRef]

39. Aquila, I.; Sacco, M.A.; Ricci, C.; Gratteri, S.; Montebianco Abenavoli, L.; Oliva, A.; Ricci, P. The role of the COVID-19 pandemic as a risk factor for suicide: What is its impact on the public mental health state today? Psychol. Trauma Theory Res. Pract. Policy 2020, 12, S120-S122. [CrossRef] [PubMed]

40. Prado, A.D.S.; Freitas, J.D.L. Social distancing during pandemics: Suicide risk and prevention in the face of psychosocial impacts of COVID-19. Estud. Psicol. (Natal) 2020, 25, 157-166. [CrossRef]

41. Mamun, M.A.; Bhuiyan, A.I.; Manzar, D. The first COVID-19 infanticide-suicide case: Financial crisis and fear of COVID-19 infection are the causative factors. Asian J. Psychiatry 2020, 54, 102365. [CrossRef]

42. Madanes, S.B.; Levenson-Palmer, R.; Szuhany, K.L.; Malgaroli, M.; Jennings, E.L.; Anbarasan, D.; Simon, N.M. Acute Stress Disorder and the COVID-19 Pandemic. Psychiatr. Ann. 2020, 50, 295-300. [CrossRef]

43. Mertens, G.; Gerritsen, L.; Duijndam, S.; Salemink, E.; Engelhard, I.M. Fear of the coronavirus (COVID-19): Predictors in an online study conducted in March 2020. J. Anxiety Disord. 2020, 74, 102258. [CrossRef] [PubMed]

44. Farooq, S.; Tunmore, J.; Ali, M.W.; Ayub, M. Suicide, self-harm and suicidal ideation during COVID-19: A systematic review. Psychiatry Res. 2021, 306, 114228. [CrossRef]

45. Cukrowicz, K.C.; Brown, S.L.; Roush, J.F. Suicidal behavior in late life. In Advancing the Science of Suicidal Behavior: Understanding and Intervention; Lamis, D.A., Kaslow, N.J., Eds.; Nova Science Publishers: New York, NY, USA, 2015; pp. 197-214.

46. Banerjee, D.; Kosagisharaf, J.R.; Rao, T.S. 'The dual pandemic' of suicide and COVID-19: A biopsychosocial narrative of risks and prevention. Psychiatry Res. 2021, 295, 113577. [CrossRef] [PubMed]

47. Calati, R.; Gentile, G.; Fornaro, M.; Tambuzzi, S.; Zoja, R. Preliminary suicide trends during the COVID-19 pandemic in Milan, Italy. J. Psychiatr. Res. 2021, 143, 21-22. [CrossRef] [PubMed]

48. Behera, C.; Gupta, S.K.; Singh, S.; Balhara, Y.P.S. Trends in deaths attributable to suicide during COVID-19 pandemic and its association with alcohol use and mental disorders: Findings from autopsies conducted in two districts of India. Asian J. Psychiatry 2021, 58, 102597. [CrossRef]

49. Wang, C.; Pan, R.; Wan, X.; Tan, Y.; Xu, L.; Ho, C.S.; Ho, R.C. Immediate Psychological Responses and Associated Factors during the Initial Stage of the 2019 Coronavirus Disease (COVID-19) Epidemic among the General Population in China. Int. J. Environ. Res. Public Health 2020, 17, 1729. [CrossRef]

50. Hossain, M.; Tasnim, S.; Sultana, A.; Faizah, F.; Mazumder, H.; Zou, L.; McKyer, E.L.J.; Ahmed, H.U.; Ma, P. Epidemiology of mental health problems in COVID-19: A review. F1000Research 2020, 9, 636. [CrossRef]

51. Wang, C.; López-Núñez, M.I.; Pan, R.; Wan, X.; Tan, Y.; Xu, L.; Choo, F.; Ho, R.; Ho, C.; García, M.E.A. The Impact of the COVID-19 Pandemic on Physical and Mental Health in China and Spain: Cross-sectional Study. JMIR Form. Res. 2021, 5, e27818. [CrossRef] [PubMed]

52. Shrestha, R.; Siwakoti, S.; Singh, S.; Shrestha, A.P. Impact of the COVID-19 pandemic on suicide and self-harm among patients presenting to the emergency department of a teaching hospital in Nepal. PLoS ONE 2021, 16, e0250706. [CrossRef] [PubMed]

53. Salari, N.; Hosseinian-Far, A.; Jalali, R.; Vaisi-Raygani, A.; Rasoulpoor, S.; Mohammadi, M.; Rasoulpoor, S.; Khaledi-Paveh, B Prevalence of stress, anxiety, depression among the general population during the COVID-19 pandemic: A systematic review and meta-analysis. Glob. Health 2020, 16, 57. [CrossRef] [PubMed]

54. Gunnell, D.; Bennewith, O.; Hawton, K.; Simkin, S.; Kapur, N. The epidemiology and prevention of suicide by hanging: A systematic review. Int. J. Epidemiol. 2005, 34, 433-442. [CrossRef]

55. Castiglioni, C.; Baumann, P.; Fracasso, T. Acute pulmonary emphysema in death by hanging: A morphometric digital study. Int. J. Leg. Med. 2016, 130, 1281-1285. [CrossRef] [PubMed]

56. Hammond, D.C. Neurofeedback Treatment of Depression and Anxiety. J. Adult Dev. 2005, 12, 131-137. [CrossRef]

57. Pérez-Elvira, R.; Oltra-Cucarella, J.; Carrobles, J.; Teodoru, M.; Bacila, C.; Neamtu, B. Individual Alpha Peak Frequency, an Important Biomarker for Live Z-Score Training Neurofeedback in Adolescents with Learning Disabilities. Brain Sci. 2021, 11, 167. [CrossRef] [PubMed]

58. Pérez-Elvira, R.; Oltra-Cucarella, J.; Carrobles, J.; Moltó, J.; Flórez, M.; Parra, S.; Agudo, M.; Saez, C.; Guarino, S.; Costea, R.; et al. Enhancing the Effects of Neurofeedback Training: The Motivational Value of the Reinforcers. Brain Sci. 2021, 11, 457. [CrossRef]

59. Lee, Y.-J.; Lee, G.-W.; Seo, W.-S.; Koo, B.-H.; Kim, H.-G.; Cheon, E.-J. Neurofeedback Treatment on Depressive Symptoms and Functional Recovery in Treatment-Resistant Patients with Major Depressive Disorder: An Open-Label Pilot Study. J. Korean Med. Sci. 2019, 34, e287. [CrossRef] [PubMed]

60. Kanberg, N.; Simrén, J.; Edén, A.; Andersson, L.-M.; Nilsson, S.; Ashton, N.J.; Sundvall, P.-D.; Nellgård, B.; Blennow, K.; Zetterberg, H.; et al. Neurochemical signs of astrocytic and neuronal injury in acute COVID-19 normalizes during long-term follow-up. EBioMedicine 2021, 70. [CrossRef] 
61. DeKosky, S.T.; Kochanek, P.M.; Valadka, A.B.; Clark, R.S.B.; Chou, S.H.-Y.; Au, A.K.; Horvat, C.M.; Jha, R.M.; Mannix, R.; Wisniewski, S.R.; et al. Blood Biomarkers for Detection of Brain Injury in COVID-19 Patients. J. Neurotrauma 2021, $38,1-43$. [CrossRef]

62. Virhammar, J.; Nääs, A.; Fällmar, D.; Cunningham, J.L.; Klang, A.; Ashton, N.J.; Jackmann, S.; Westman, G.; Frithiof, R.; Blennow, K.; et al. Biomarkers for central nervous system injury in cerebrospinal fluid are elevated in COVID-19 and associated with neurological symptoms and disease severity. Eur. J. Neurol. 2021, 28, 3324-3331. [CrossRef] [PubMed]

63. Ryu, S.; Lee, H.; Lee, D.-K.; Park, K. Use of a Machine Learning Algorithm to Predict Individuals with Suicide Ideation in the General Population. Psychiatry Investig. 2018, 15, 1030-1036. [CrossRef]

64. Neamțu, B.; Visa, G.; Maniu, I.; Ognean, M.; Pérez-Elvira, R.; Dragomir, A.; Agudo, M.; Sofariu, C.; Gheonea, M.; Pitic, A.; et al. A Decision-Tree Approach to Assist in Forecasting the Outcomes of the Neonatal Brain Injury. Int. J. Environ. Res. Public Health 2021, 18, 4807. [CrossRef] [PubMed]

65. Kurihara, T.; Kato, M.; Reverger, R.; Tirta, I.G.R. Risk factors for suicide in Bali: A psychological autopsy study. BMC Public Health 2009, 9, 327. [CrossRef] [PubMed] 